\title{
The use of simulation modelling for determining the capacity of railway lines in the Czech conditions
}

https://doi.org/10.1515/eng-2020-0026

Received Oct 22, 2019; accepted Nov 20, 2019

Abstract: Simulation modelling is one way to determine the capacity of railway lines. The specialized software tool OpenTrack was used for simulation. The aim of this paper was to find out whether the OpenTrack simulation software can be used for the calculation of headway, and to compare the results with the methodology of the Railway Infrastructure Administration (SžDC). Using the software tool, a detailed transport network model can be created including all its important characteristics. The simulation follows the movements and behaviour of trains with predefined parameters on the modelled railway line. OpenTrack allows for monitoring a range of parameters including not only train delays, train conflicts and train traffic flow, but also for instance train energy performance and headways. During the first stage of work with OpenTrack, a simulation model was created, not reflecting any existing infrastructure but including parameters typical of railway lines in the Czech Republic, such as the configuration of gridirons, length of station tracks, size of block sections, etc. This model was subsequently used for the simulation of type train set journeys, and a headway calculator was used for the calculation of headway values. These values were compared with the methodology used by the Railway Infrastructure Administration. The paper is concluded by the comparison of the above mentioned approaches.

Keywords: simulation, capacity, modelling, railway lines

\footnotetext{
*Corresponding Author: Jaromır Široký: University of Pardubice, Faculty of Transport Engineering, Department of Transport technology and control, Studentská 95, Pardubice, Czech Republic; Email: jaromir.siroky@upce.cz

Erik Tischer, Petr Nachtigall: University of Pardubice, Faculty of Transport Engineering, Department of Transport technology and control, Studentská 95, Pardubice, Czech Republic
}

\section{Introduction}

Usable capacity is one of the key factors determining the transport possibilities of railway infrastructure. Mostly analytical methods are currently used for its assessment. In the Czech Republic, mostly the ČD D24 methodology had been used for capacity assessment until it was replaced in June 2019 by the new SŽDC SM 124 - Establishing Railway Capacity directive $[1,2]$. Another way of establishing railway capacity is the methodology described in UIC Codex 406 - Capacity [3]. Both these methodologies are primarily based on the assumption that railway line can be described as a bulk servicing system with an unlimited supply of input parameters (there is always a train available). However, the most prevalent mode of traffic is currently passenger transport with periodic timetables. Such traffic characteristics result in the distortion of results achieved with analytical methods for establishing usable capacity of lines. In periodic timetables, there is an increased number of additional occupancy times which are difficult to quantify [4]. At the same time, there is an increase in the range of variants of train speed, which leads to an even greater distortion of the results of analytical methods and a decrease in the actual usable capacity of railway infrastructure. Considering the constant development of methodologies in determining the capacity of railway lines, the SŽDC SM 124 directive allows for the use of computer simulation as well. This methodology describes the possible approaches to the use of simulation and sets out the indicators to be used for railway line capacity assessment [5].

The use of simulation modelling opens up new possibilities in determining railway line capacity. Simulation allows for checking the usable capacity of any part of railway infrastructure taking into account local specificities and traffic characteristics [6]. However unlike in analytical methods, the output of simulation is not a specific value describing the usable capacity of the line. The output of simulation is an analysis of specific operational situations and of the stability of the proposed timetable and the determination of bottlenecks in the transport network con-

○ Open Access. (c) 2020 E. Tischer et al., published by De Gruyter. (CC) BY 4.0 License 
sidered. For the simulation results to be correctly generalized, there have to be multiple experiments, and multiple possible operational scenarios have to be examined. For this purpose, a railway infrastructure model is currently being devised at the Department of Transport Technology and Control of the Faculty of Transport Engineering of the University of Pardubice for assessing the new possibilities of using computer simulation in railway line capacity determination. The model has been created in the OpenTrack software, which has been designed for railway traffic modelling. This paper describes OpenTrack and the modelling therein. At the same time, the first results are presented here which were obtained using the model. To verify the functioning of the model and explore the possibilities of the use of OpenTrack, we decided to determine headways for selected train categories. The amount of headway is one of the key components of line capacity assessment.

\section{Simulation model preparation}

The simulation was made in the OpenTrack simulation software used for the simulation of operation of any type of rail transport. Designed by the Swiss Federal Technology Institute for Transport Planning and Systems, the software is already widely used in the Czech Republic. OpenTrack is mainly used for assessing the capacity of railway infrastructure or other types of rail infrastructure, for evaluating the stability of proposed timetables and for testing the train energy performance. The input data for the simulation model is data on infrastructure, vehicles and timetables. The software has been designed in a way that it allows for creating a model respecting the specificities of different railway systems, including mainly the different transport and signal regulations and the particular characteristics of train safety devices [6-8].

Every transport model is a certain simplification of the actual infrastructure and traffic. Such simplification can indeed lead to a certain distortion of results as well. The advantage of OpenTrack is the fact that it allows for including all relevant parameters in the model for it to be as realistic as possible. The level of detail of the model needs to be set in a way to contain all important parameters that can have an impact on the results of the subsequent simulation. OpenTrack is especially suitable for designing microscopic or mesoscopic simulation models. The simulation model is made in three steps. The first step involves the creation of a transport network model. In the second and third steps, vehicle data and timetable data is fed to the model, respectively $[9,10]$.
In the first step, infrastructure data is fed to the model. The infrastructure (transport network) is represented by a network graph. The vertices of this graph represent the kilometre position of locations on the infrastructure where its decisive parameters are changed. The vertices also represent the kilometre position of devices for the organization and control of railway traffic including signal points, track circuits, axle counters, switches, fouling point markers, crossings, platforms, stations and stops. The defined vertices are connected through edges representing the individual tracks. These edges are assigned the gradients and alignments of the corresponding line sections [11].

The transport network graph is fed with the parameters of different routes which can be used in the simulation model. The station routes are defined by interlocking tables determining the dependencies of the position of individual elements in the route. The routes are fed in three steps. In the first step, the routes are defined and assigned to different signal points. This step also involves defining the mutual dependencies of the routes and inputting parameters corresponding to individual types of station and rail safety devices. These parameters mainly include the reaction times of safety devices and the times of route setting and cancellation. OpenTrack searches for these routes automatically. From this set of routes, the routes which are acceptable for the given model are selected manually. The second step involves the creation of combined routes, i.e. paths. These combined routes are made of one or several consecutive routes. The paths define the proposed shortest possible train journeys in the model. At the same time, this step simplifies the subsequent feeding of train journey itineraries. The third step involves feeding the journey itineraries of the individual trains (or groups of trains). Made of the individual paths, the itineraries define the rail and station tracks to be used by the train during its journey. Every line input can be made of several itineraries for which it is necessary to define their priority. Based on the availability of different routes, OpenTrack selects the itinerary with the greatest priority. However, this function cannot replace a sophisticated technology respecting the traffic control rules. Without external interventions in the simulation, the software can only perform dispatching control to a limited extent.

After feeding the infrastructure parameters and routes, it is necessary to feed the model with vehicle data as well. The first step involves feeding the data on traction units including the traction unit name, weight, adhesion weight, length, maximum speed, traction power supply system, traction performance, coefficients of running and vehicle resistance and type of train protection system used. In the second step, different types of trains are fed using 
a train editor. Every train is assigned a type of traction unit and other parameters, such as: train category, weight, maximum acceleration value, traction rise time, braking characteristics and drag coefficient.

To be able to simulate the proposed operational concepts, timetables have to be input as well. In this step, a particular train is assigned a number, category, manner of line occupation, temporal position and specific itineraries with set preferences [12]. If for the simulation there is no available timetable designed in another way, it has to be created. This is possible by starting the simulation and obtaining the necessary travel times and technological times.

\section{Data and methods}

Simulation modelling is one of the possible tools for assessing the possibilities of railway infrastructure. Between 2005 and 2015, more than 50 capacity assessing studies were carried out in the United States and in Europe. About $65 \%$ of these studies use simulation or combined methods. In addition to OpenTrack, the following tools have been used for simulation: MultiRail (United States), RAILSIM (United States), SIMONE (Netherlands), RailSys (Germany), DEMIURGE (France), RAILCAP (Belgium) a CMS (Great Britain). The capacity assessment studies mostly resulted in proposing measures to increase the capacity. Out of the 25 studies examined in detail, in 14 cases the results were at least partially validated, but only two studies involved a complete validation of the results based on experience with their practical implementation. At the same time it was found out that no two approaches to using simulation in capacity assessment are completely identical. The different studies always reflect the national specificities and approaches to railway traffic control and organization [13]. In this section of the paper, three studies will be briefly described where capacity was assessed using OpenTrack.

The first study deals with assessing the capacity of the line Zagreb - Rijeka M202 (Croatia), which is part of the TEN-T network. The purpose of the study was to explore the possibilities of future capacity increase after line reconstruction. In the study, the traffic organization was changed to increase the capacity for freight transport. The simulation showed that by reconstructing the line and changing the traffic organization, the line capacity for freight transport would increase by $23 \%$ [14].

The second study dealt with the reconstruction of the line R 201 Zaprešić - Zabok (Croatia). In this study, OpenTrack was used to simulate a future timetable. The study also examined which train protection system would be suitable. However, in simulating the different scenarios, the benefits of implementation of the ETCS system compared to the national train protection system were not clearly demonstrated. The study assessed the benefits of reconstruction in increasing the line attractiveness and capacity [15].

The third study deals with traffic simulation on the Beijing - Shanghai high-speed railway. This study examined the impact of shortening headways on increasing the line capacity. The initial headway was set at 5 minutes. Different scenarios were simulated with a progressive decrease of headways to the final value of 3 minutes. What turned out to be a limiting factor was the time spent at stations, and that's why in reducing headways, the time spent at stations had to be shortened or individual groups of stations had to be skipped. At the same time, considering the length of the section in question $(1,318 \mathrm{~km})$, it wasn't possible to simulate the entire line length. Shortening the headway from five to three minutes would theoretically increase the capacity by $72.7 \%[8]$.

\section{Test infrastructure model}

To explore new methods of assessing the capacity of railway lines using simulation, a fictitious railway infrastructure model was designed in OpenTrack at the Department of Transport Technology and Control of the Faculty of Transport Engineering. Since in research, the focus is on modern railway infrastructure, also this model was designed only with modern infrastructure elements, safety devices and vehicles.

A line was designed with a total length of $18.35 \mathrm{~km}$ with three through stations and three stops. The line model was designed to form an endless loop. Three interstation sections were created, each with one stop. The line is double-tracked in its entire length. After eliminating other undesirable input variables, the line has the same vertical alignment in its entire length and contains no curves. All three stations are four-tracked with a different arrangement and length of station gridirons and tracks between the home signal and the outside switch. On gridirons, switches were used with a speed range in diverging track between 40 and $80 \mathrm{~km} \cdot \mathrm{h}^{-1}$. The stops are located relative to the location of section signal devices and stations in a way that they allow for the monitoring of their most appropriate positioning for the best possible usable capacity of the given interstation section. Figure 1 shows a model of one of the stations (Station A). 


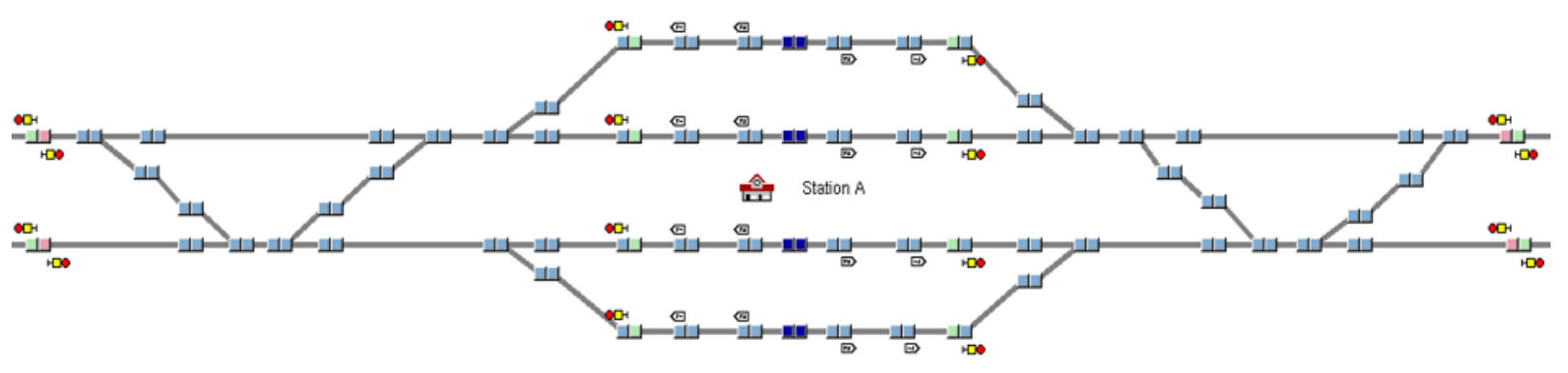

Figure 1: Model Station A

Safety devices in the stations are modelled to meet the parameters of an electronic signal box. At the stations, there are dependent signal devices with a speed signalling system. Line sections are fitted with a bidirectional three-element automatic block with five or six sections of $1,000 \mathrm{~m}$. The length of line sections adjacent to the stations indeed depends on the length of the station gridirons and of the tracks between the home signal and the outside switch, and thus on the distance between the starting sig nals and block signals.

\section{Headway}

The term headway, expressed by the unknown M, has been defined in literature [16]. Its value is established as the maximum value of three partial values (front operating post partial headway, rear operating post partial headway and line partial headway). The line partial headway is established as the maximum value of partial headways for the individual block sections. The correct determination of headway is very important not only for the calculation of capacity, but mainly for the creation of a stable train diagram and for a continuous traffic flow. According to the general rules of the Railway Infrastructure Administration methodology, this headway is rounded to the nearest half minute. However, the calculation itself allows for determining the headway with an accuracy of seconds.

After creating the test infrastructure model, headway was calculated using the OpenTrack tool called headway calculator. This tool allows for determining the headway of two trains. Through multiple simulations, different headway values are tested and using the bisection method, the final value is determined which meets the given conditions. The basic scenario involves determining the value for a conflict-free train diagram. Setting the calculator in different ways, it is possible to test conflicting variants as well (where the other train has to brake before the advance sig- nal, before the home signal or it has to stop). These scenarios can for example be used for peak hours.

For the headway simulation, rules were defined determining the behaviour of different train pairs depending on the order of importance. The train order of importance is based on the SŽDC D1 regulation - Transport and Signal Regulation [17]. The rules for arrival and departure headways are defined as follows:

- Arrival headway rules

- Where the train categories are the same, the 1 st train goes directly, the 2nd one takes the passing track.

- Where the 1st train is of higher category, it goes directly, and the 2nd one takes the passing track.

- Where the 1st train is of lower category, it takes the passing track, and the 2nd one goes directly.

- Where the 1st train is of Os category and the 2nd one is of Nex or Pn categories, the 1st train always goes directly, and the 2nd one takes the passing track.

- Departure headway rule - the 1 st train always departs from the main track, the 2nd train takes the passing track (from the standstill).

At the same time, a single policy was created for the stopping of passenger trains and the time they spend at stations and stops. All trains of $R$ and $O s$ categories stop at stations $A, B$, and $C$. They stay there for 60 seconds. At stops, only Os category trains stop, spending there 30 seconds [18].

For the purposes of the simulation, it was necessary to enter the train set parameters to OpenTrack. Five type train sets were selected representing trains that are commonly used on the Railway Infrastructure Administration network. Their parameters are provided for in Table 1. 
Table 1: Parameters of type train sets used

\begin{tabular}{cccccc}
\hline $\begin{array}{c}\text { Train } \\
\text { category }\end{array}$ & Train name & Traction unit & $\mathrm{V}_{\max }$ & $\begin{array}{c}\text { Train set } \\
\text { length }\end{array}$ & $\begin{array}{c}\text { Train set } \\
\text { weight }\end{array}$ \\
\hline Nex & Container train & TRAXX F 140 MS & $120 \mathrm{~km} \cdot \mathrm{h}^{-1}$ & $600 \mathrm{~m}$ & $1,000 \mathrm{t}$ \\
$\mathrm{Pn}$ & Coal & ČD Cargo 363.5 & $80 \mathrm{~km} \cdot \mathrm{h}^{-1}$ & $600 \mathrm{~m}$ & $1,800 \mathrm{t}$ \\
Os & CityElephant & 471 & $140 \mathrm{~km} \cdot \mathrm{h}^{-1}$ & $80 \mathrm{~m}$ & $155 \mathrm{t}$ \\
$\mathrm{R}$ & InterPanter & 661 & $160 \mathrm{~km} \cdot \mathrm{h}^{-1}$ & $132 \mathrm{~m}$ & $170 \mathrm{t}$ \\
$\mathrm{Ex}$ & Pendolino & 680 & $200 \mathrm{~km} \cdot \mathrm{h}^{-1}$ & $185 \mathrm{~m}$ & $385 \mathrm{t}$ \\
\hline
\end{tabular}

Table 2: Results provided by the headway calculator for one of the sections

\begin{tabular}{|c|c|c|c|c|c|c|c|c|c|c|c|}
\hline \multicolumn{12}{|c|}{ Line section $B-C$} \\
\hline & & \multicolumn{10}{|c|}{ Train 1} \\
\hline \multirow{7}{*}{ 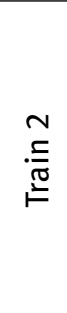 } & & \multicolumn{2}{|c|}{ Nex } & \multicolumn{2}{|c|}{$\mathrm{Pn}$} & \multicolumn{2}{|c|}{ Os } & \multicolumn{2}{|c|}{$R$} & \multicolumn{2}{|c|}{ Ex } \\
\hline & & Arriv. & Dep. & Arriv. & Dep. & Arriv. & Dep. & Arriv. & Dep. & Arriv. & Dep. \\
\hline & Nex & 84 & 73 & 205 & 106 & 155 & 126 & 85 & 80 & 38 & 38 \\
\hline & $\mathrm{Pn}$ & 73 & 73 & 106 & 106 & 105 & 76 & 80 & 80 & 38 & 38 \\
\hline & Os & 73 & 73 & 128 & 113 & 135 & 136 & 80 & 80 & 38 & 38 \\
\hline & $\mathrm{R}$ & 141 & 73 & 219 & 175 & 192 & 154 & 80 & 149 & 38 & 38 \\
\hline & Ex & 200 & 73 & 278 & 153 & 251 & 148 & 172 & 127 & 62 & 38 \\
\hline
\end{tabular}

Table 3: Results of the headway calculator after maximization

\begin{tabular}{|c|c|c|c|c|c|c|}
\hline \multicolumn{7}{|c|}{ Line section $B-C$} \\
\hline & & \multicolumn{5}{|c|}{ Train 1} \\
\hline \multirow{6}{*}{ 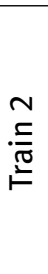 } & & Nex & $\mathrm{Pn}$ & Os & $\mathrm{R}$ & Ex \\
\hline & Nex & 84 & 205 & 155 & 85 & 38 \\
\hline & $\mathrm{Pn}$ & 73 & 106 & 105 & 80 & 38 \\
\hline & Os & 73 & 128 & 136 & 80 & 38 \\
\hline & $\mathrm{R}$ & 141 & 219 & 192 & 149 & 38 \\
\hline & Ex & 200 & 278 & 251 & 172 & 62 \\
\hline
\end{tabular}

Source: Authors

\section{Headway simulation using headway calculator}

Using the infrastructure and train sets, the simulation was performed to determine the headway values for different train combinations. Each of the train pairs was simulated separately on all interstation sections in two scenarios (arrival at the front operating post and departure from the rear operating post).

The output is six tables containing the headway values in seconds for different train combinations. The final headway value is calculated as the maximum value from each pair of values. One such pair is highlighted in bold in Table 2.
The result is Table 3 only containing values corresponding to the maximum value from each pair of elements.

These results were compared with those obtained by the method described in literature [19, 20]. A total of twelve train pairs was selected for the headway calculation.

For the calculation of travel times necessary for the analytical calculation of headways, the measuring instrument was used which allows for monitoring the current speed and current time of passing a given point in the network. Subsequently, partial headways were calculated using formula (1).

$$
M=\max \left(M_{Z}, M_{P}, M_{T}\right) \quad[\min ]
$$

where: $M_{Z}$ is the rear operating post partial headway, $M_{P}$ is the front operating post partial headway,

$M_{T}$ is the line operating post partial headway (maximum headway value in case of more line sections).

The values of different operating intervals and partial headways are composed of five partial times. This calculation is made using formula (2).

$$
M_{Z, P, T}=j_{1}+r+p+j_{2}+d \quad[\min ]
$$

Where: $j_{1}$ is the first train journey until the time of leaving the place of danger (switch, block section, etc.)

$r$ is the route cancellation time after the first train (safety device reaction)

$p$ is the preparation of the route for the second train (safety 
Table 4: Calculation of headways according to SM 104

\begin{tabular}{|c|c|c|c|c|c|c|c|}
\hline \multirow{2}{*}{\multicolumn{2}{|c|}{$\begin{array}{l}\text { Interstation section } \\
\text { Trains assessed }\end{array}$}} & \multicolumn{6}{|c|}{$B-C$} \\
\hline & & \multirow{2}{*}{ Train 1} & \multicolumn{2}{|c|}{ Os } & \multirow{2}{*}{ Train 2} & \multicolumn{2}{|c|}{ Os } \\
\hline & & & \multicolumn{4}{|c|}{ leadway components } & \\
\hline $\bar{M}$ & Place of danger & j1 & & $\mathrm{p}$ & $\mathrm{j} 2$ & $\mathrm{~d}$ & $M$ \\
\hline$M_{Z 1}$ & Station A (dep. gridiron) & 16 & 6 & 6 & 0 & 18 & 46 \\
\hline$M_{Z 2}$ & Section 1 & 70 & 6 & 12 & 0 & 18 & 106 \\
\hline $\mathbf{M}_{T 1}$ & Section 2 & 97 & 3 & 3 & 0 & 12 & 115 \\
\hline $\mathbf{M}_{T 2}$ & Section 3 & 197 & 3 & 3 & -68 & 18 & 153 \\
\hline $\mathrm{M}_{T 3}$ & Section 4 & 228 & 3 & 3 & -94 & 12 & 152 \\
\hline $\mathrm{M}_{T 4}$ & Section 5 & 254 & 3 & 3 & -193 & 12 & 79 \\
\hline $\mathrm{M}_{P 1}$ & Station B (arriv. gridiron) & 278 & 6 & 12 & -226 & 12 & 82 \\
\hline$M_{P 2}$ & Station B (station track) & 279 & 3 & 3 & -226 & 12 & 71 \\
\hline \multicolumn{2}{|c|}{ Resulting headway } & \multicolumn{5}{|c|}{ Maximum value from column $M$} & 153 \\
\hline \multicolumn{2}{|c|}{ Simulation result } & \multicolumn{5}{|c|}{ Simulated headway value } & 136 \\
\hline \multicolumn{2}{|c|}{ Verifying calculation } & \multicolumn{5}{|c|}{ Value after adding static component $d$} & 154 \\
\hline
\end{tabular}

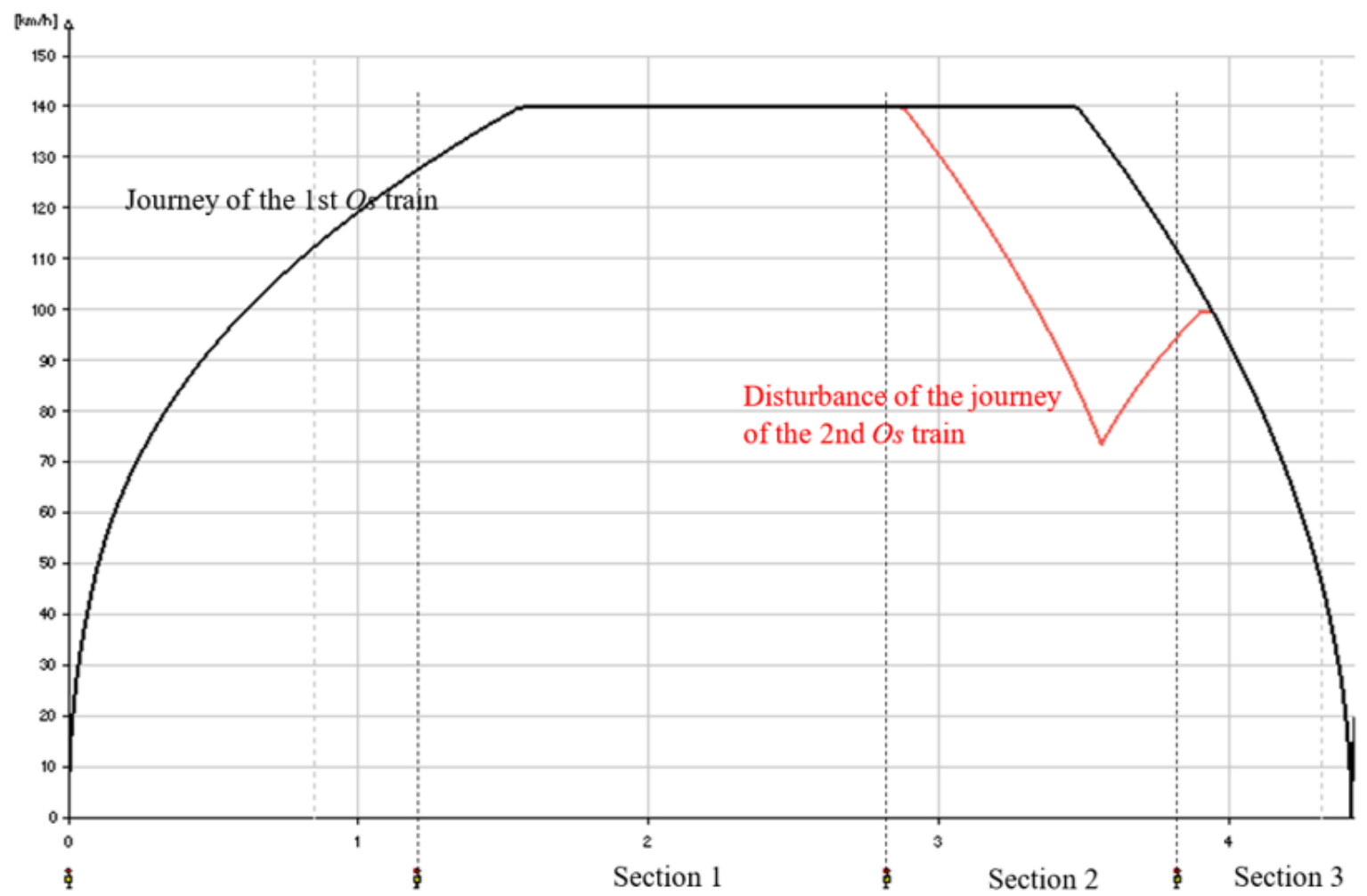

Figure 2: Graph of the journey of subsequent Os trains

device operation)

$j_{2}$ is the second train journey since the time of occupation $d$ is the signal visibility or second train departure

Only the dynamic component $j_{1}$ is related to the first train journey in this method. Other times are related to the second train journey. The dynamic component of the second train is always calculated based on the reference time, i.e. from the moment when the first time left the decisive elements of infrastructure. For the sake of clarity of the calculation, for each train pair a table was created containing 
Table 5: Comparison of headway values

\begin{tabular}{|c|c|c|c|c|c|}
\hline Section & First train & Second train & $\begin{array}{l}\text { Headway } \\
\text { (OpenTrack simulation) }\end{array}$ & $\begin{array}{l}\text { Headway } \\
\text { (SM } 104 \text { methodology) }\end{array}$ & Difference \\
\hline$A-B$ & Nex & Nex & 96 & 98 & $-2.04 \%$ \\
\hline$A-B$ & $\mathrm{Pn}$ & Nex & 254 & 255 & $-0.39 \%$ \\
\hline$B-A$ & $\mathrm{Pn}$ & $\mathrm{Pn}$ & 114 & 113 & $0.88 \%$ \\
\hline$B-A$ & Os & Pn & 130 & 122 & $6.56 \%$ \\
\hline$B-C$ & Os & Os & 155 & 154 & $0.65 \%$ \\
\hline$B-C$ & $\mathrm{R}$ & Os & 105 & 98 & $7.14 \%$ \\
\hline$C-B$ & $\mathrm{R}$ & $\mathrm{R}$ & 123 & 122 & $0.82 \%$ \\
\hline$C-B$ & $\mathrm{R}$ & Ex & 203 & 197 & $3.05 \%$ \\
\hline$C-A$ & Ex & Ex & 88 & 89 & $-1.12 \%$ \\
\hline$C-A$ & Nex & Ex & 239 & 241 & $-0.83 \%$ \\
\hline$A-C$ & Os & $\mathrm{R}$ & 173 & 165 & $4.85 \%$ \\
\hline$A-C$ & $\mathrm{Pn}$ & Ex & 307 & 307 & $0.00 \%$ \\
\hline \multicolumn{5}{|c|}{ Average difference of headway values } & $1.33 \%$ \\
\hline
\end{tabular}

headway values, from which the maximum value was selected representing the decisive headway [21]. In addition to the maximum headway values, the Table 4 indicates the limiting infrastructure section as well. To illustrate the calculation (Table 4), the interstation section B - C and headway for $O s-O s$ trains were selected.

\section{Results and Discussion}

From the results provided in Table 4, it is clear that even after adding the static component $d$ (departure of the second train from the stop), the results differ from those of the simulation by one second. This deviation can be considered a measurement error. The static component $d$ can be integrated in the simulation model, or subsequently added like in this case. Analytical calculations validated the model and its functioning for establishing headways. Just like in the example provided above, the maximum difference between the results of the simulation and analytical calculation was in the ones of seconds.

As can be seen from Table 4, limiting is interstation section 3 as it contains stop (Stop BC), where Os trains stop. This limiting section can also be identified through the simulation. Figure 2 shows a graph of $O s$ train journey. As can be seen from the graph, the journey of the second train is disturbed where the headway calculated in Table 4 is not observed. This leads to slowing down the journey of the subsequent train due to braking before the occupied interstation section.
To assess the validity of the resulting headway values obtained through the simulation, Table 5 was created comparing these values with headway values established in accordance with the methodology described in literature [20]. The average difference between the results obtained is $1.33 \%$. Table 5 shows the percentage difference for all the twelve cases assessed.

\section{Conclusion}

The main question to be answered by this paper was whether it is possible to use the OpenTrack software for simulations in calculating the capacity of railway lines in Czech conditions. A fictitious infrastructure was created and used for the simulation of actual type train sets to determine the headway values. By comparing the simulation results and the calculations made according to the Railway Infrastructure Administration (SŽDC), it was established that the approaches are mutually consistent, with the difference between the calculated values being less than $1.5 \%$ on average. As such, our research has shown that it is possible to use OpenTrack for traffic simulation on Czech infrastructure and that the results of headway calculations are consistent with those provided in literature $[5,16]$. This underlying assumption can serve as a basis for further research in this field and for the use of OpenTrack as a tool for assessing the railway line capacity in the Czech Republic. 
Acknowledgement: The work was supported from ERDF/ESF "Project PosiTrans - University of Pardubice cooperation and application sphere in application oriented research of localization, detection and simulation systems for transport processes" (No. CZ.02.1.01/0.0/0.0/17_049/0008394).

\section{References}

[1] SŽDC SM 124 directive - Establishing Railway Capacity with effect from 07 June 2019, Praha, railway infrastructure manager - SŽDC.

[2] Codex UI. 406 - Capacity. 1st ed. Paris: UIC International Union of Railways; 2004.

[3] Molková T, et al. Determining the capacity of railway lines. Pardubice: University of Pardubice; 2010.

[4] Huerlimann D, Nash AB. OpenTrack Simulation of Railway Network, Version 1.9, Manual. OpenTrack Railway Technology Ltd. and ETH Zurich Institute for Transport Planning and Systems; 2017.

[5] Pouryousef H, Lautala P, White T. Railroad capacity tools and methodologies in the U.S. and Europe. Journal of Modern Transportation. 2015;23(1):30-42.

[6] Ljubaj I, Mlinarić TJ, Radonjić D. Proposed solutions for increasing the capacity of the Mediterranean Corridor on section Zagreb-rijeka. Procedia Eng. 2017;192:545-50.

[7] Ljubaj I, Mlinarić T, Ležaić T, Starcevic M. The Possibility of Capacity Increase on the Modernised and Electrified Railway Line R201 along the Zaprešić - Zabok Section, 2018, MATEC Web of Conferences. 235. 00009. DOI: https://doi.org/10.1051/matecc onf $/ 201823500009$.

[8] Chen Z., Han B. M., Simulation Study Based on OpenTrack on Carrying Capacity in District of Beijing-Shanghai High-Speed Railway, Applied Mechanics and Materials, 2014, 505-506, 567570. DOI: 10.4028/www.scientific.net/AMM.505-506.567.

[9] Żardecki, D., Jemiot, L., Gidlewski, M. Simulation investigation of the dynamics of the process of sudden obstacle avoiding by a motor vehicle. The Archives of Automotive Engineering - Archiwum Motoryzacji, 73(3). 2016. DOI: https://doi.org/ 10.14669/AM.VOL73.ART3.

[10] Poliakova B, Kubasakova I, Kubanova J. Closed System Simulation in the Road Freight Transport. In: 19th International Scientific Conference on Transport Means 2015, Kaunas, Lithuania, OCT 22-23, 2015, pp. 199-202.
[11] Chovancová M, Stopka 0, Klapita V. Modeling the distribution network applying the principles of linear programming. In: 21st International Scientific on Conference Transport Means 2017, Juodkrante; Lithuania; 20-22 September 2017, Code 135093, 2017, pp. 73-77. ISSN 1822-296X.

[12] Sarkan B, Stopka O, Chovancova M, Kuranc A. Simulating Real Driving Conditions on the Single Roller Dynamometer: a Case Study in Terms of the Fuel Consumption Measurement. Book Group Author(s): IEEE, 11th International Scientific and Technical Conference on Automotive Safety, Casta Papiernicka, Slovakia, April 18-20, 2018. ISBN 978-1-5386-4578-9. https://doi.org/ 10.1109/AUTOSAFE.2018.8373313.

[13] Gasparik, J., Majercak, J., Siroky, J., Abramovic, B., Mesko, P., Nachtigall, P., Zitricky, V. Railway Traffic Operation, 2017, 239 270.

[14] Abramović B. Passenger's satisfaction on long distance terminals: case study city of Zagreb. Periodica Polytechnica Transportation Engineering. 2017;45(1):42-7.

[15] Ondrus J, Karon G. Video System as a Psychological Aspect of Traffic Safety Increase. In: 17th International Conference on Transport Systems Telematics (TST), Katowice, Poland, April 05-08, 2017; Communications in Computer and Information Science, 715, pp. 167-177.

[16] SŽDC SM 104 directive - Operating Intervals and Headways with effect from 01 October 2013, Praha, railway infrastructure manager - SŽDC.

[17] SŽDC D1 regulation - Transport and Signal Regulation with effect from 01 July 2013, Praha, railway infrastructure manager - SŽDC.

[18] Hlatka M, Bartuska L, Lizbetin J. Application of the Vogel Approximation Method to Reduce Transport-logistics Processes, 2017, MATEC Web of Conferences, 134, Article no. 00019, In: 18th International Scientific Conference on LOGI, Ceske Budejovice, Czech Republic, October 19, 2017. https://doi.org/10.1051/matecc onf/201713400019.

[19] L'upták V, Stopka O, Jeřábek K. Draft deployment of traction units with active tilting system for regional and long-distance transport on non-modernized railway tracks. MATEC Web of Conferences, Vol. 134, Article number 00034, 18th International Scientific Conference, LOGI 2017; Ceske Budejovice; Czech Republic; 19 October 2017 through; Code 131750. DOI: https://doi.org/ 10.1051/matecconf/201713400034.

[20] Neradilova H, Fedorko G, Borsosova V. Modelling of Intra Plant Transportation System Using AGV, In: Proc. third Int. Conf. Traffic. Transp. Eng., 2016, pp. 971-979.

[21] Stopka O, Kampf R. Determining the most suitable layout of space for the loading units' handling in the maritime port. Transport. 2018;33(1):280-90. 